\title{
Cold Crack Criterion for ADC12 Aluminum Alloy Die Casting*
}

\author{
Shuxin Dong, Yasushi Iwata, Yoshio Sugiyama and Hiroaki Iwahori \\ Materials Fundamental Research Division, Toyota Central R\&D Labs., Inc., Aichi 480-1192, Japan
}

A cold crack criterion for JIS ADC12 aluminum alloy die casting is proposed. Through investigating the temperature dependence of the fracture strain of JIS ADC12 aluminum alloy die casting, it was found that the fracture strain features a turning point at a temperature, $T_{\mathrm{c}}$ (we called "critical temperature to the ductility", about $573 \mathrm{~K}$ for the present composition), i.e. stays low while below $T_{\mathrm{c}}$, rises rapidly to a high level beyond $T_{\mathrm{c}}$. Focusing on this character of the fracture strain, we analyzed the equivalent plastic strain $\left(\varepsilon_{\mathrm{c}}\right)$ of the castings introduced below $T_{\mathrm{c}}$ in casting processes by thermal stress simulations and compared with the occurrence of cold cracks in the die casting experiments. It was found that the $\varepsilon_{\mathrm{c}}$ of the cracking positions in the castings exceeded, while the $\varepsilon_{\mathrm{c}}$ of the castings without crack were much lower than the fracture strain of JIS ADC12 aluminum alloy die casting below $T_{\mathrm{c}}$. That is to say, the occurrence of the cold crack in a die casting can be judged by comparing the $\varepsilon_{\mathrm{c}}$ with the fracture strain below $T_{\mathrm{c}}$. Based on this proposed criterion, it is possible to predict the appearance of the cold cracks in ADC12 die castings by thermal stress simulations. [doi:10.2320/matertrans.F-M2009832]

(Received August 6, 2009; Accepted November 6, 2009; Published December 23, 2009)

Keywords: aluminum alloy, die casting, defect, cold crack, strain, simulation

\section{Introduction}

The production of aluminum alloy die castings has been seeing a continuous increase to answer the strong demand by the automotive industry for higher strength and lighter weight. The die castings for automotives are required of not only high quality as of course but also thin walls and a high dimensional precision, thus it is essential to provide advanced casting technologies for the manufacturing of these castings. The cold crack of castings, which was not considered as a serious problem before, has become one of the most important subjects together with the security of the dimensional precision in the die casting production.

It is crucial to predict the occurrence of cracks by numerical simulations based on their formation mechanisms in order to prevent such defects. Although many excellent thermal and stress simulation techniques have been developed for die casting processes, we still have difficulties in predicting the occurrence of such cracks accurately. ${ }^{1)}$ One reason for such a situation can be attributed to the lack of the knowledge of the cold crack formation conditions.

The cracks in die castings, according to their occurrence time in the casting process, can be classified into 2 types, i.e., one forms during the solidification and another forms during the cooling after the solidification. ${ }^{2-4)}$ The former, called hot crack or hot tear, happens at the low ductility temperature range around the solidus temperature of cast alloys, while the latter, named cold crack, appears at lower temperature in the cooling process. The hot cracks show fractographies of dendrites or solidified liquid metal films, while the cold cracks have fractographies like that of general mechanically fractured metals. A large number of researches have been made on the hot cracks encountered in continuous casting and shape casting processes and several formation mechanisms have also been proposed, ${ }^{5-9)}$ while few researches can be found on the cold crack in the literature. With the progress of thinner walls and a higher dimension precision of the die castings, the problem of the cold cracks resulting from the

*This Paper was Originally Published in Japanese in J. JFS 81 (2009) 226 231. restraints of molds, inserts or casting itself is becoming more and more obvious and the prediction technology for this defect is much desired. Although the cold cracks occur in solid metals of which the fracture theory has been fairly well established at some definite temperature, the formation condition is still left to be revealed. That is because these cracks originate in the continuous cooling process of solid metals in a temperature range of several hundred degrees. Such a large range of temperature change makes it difficult to understand the occurrence condition of the cold cracks because the mechanical properties of metals, such as ultimate strength, fracture strain, etc., may change radically.

In order to clarify the formation condition of the cold crack occurring in JIS ADC12 aluminum alloy (hereinafter, called ADC12 alloy) die castings, we produced the defects by die casting experiments and investigated the temperature dependence of the fracture strain of ADC12 alloy by tensile tests, then traced the strain in the die casting processes by numerical simulations of thermal stress.

\section{Experimental and Simulation Methods}

\subsection{Castings and casting method}

The die casting shown in Fig. 1 was used for the experiments producing the cold cracks. Two rings made of SUS304 stainless steel (hereinafter, called SUS304) were set in the inner side of the cylinder-shaped cavities of the mold as inserts before casting. The die casting conditions are given in Table 1 . The mold was kept at room temperature (298 K) and JIS AD12.1 aluminum alloy melt (hereinafter, called AD12.1 alloy melt) of the chemical composition shown in Table 2 was shot into the mold vertically from the lower side at $913 \mathrm{~K}$. The distance between the SUS304 rings was changed from 1 to $5 \mathrm{~mm}$ intentionally attempting to produce the crack in the casting between the two rings. The outer surfaces of rings which contact the melt in the casting were finished to a surface roughness of $50 \mu \mathrm{m}$ with lathe. To detect the occurrence time of the cracks in the casting, a high temperature strain gage was installed to the inner surface (the surface contacts the mold) of one SUS304 ring in the circumferential direction. 


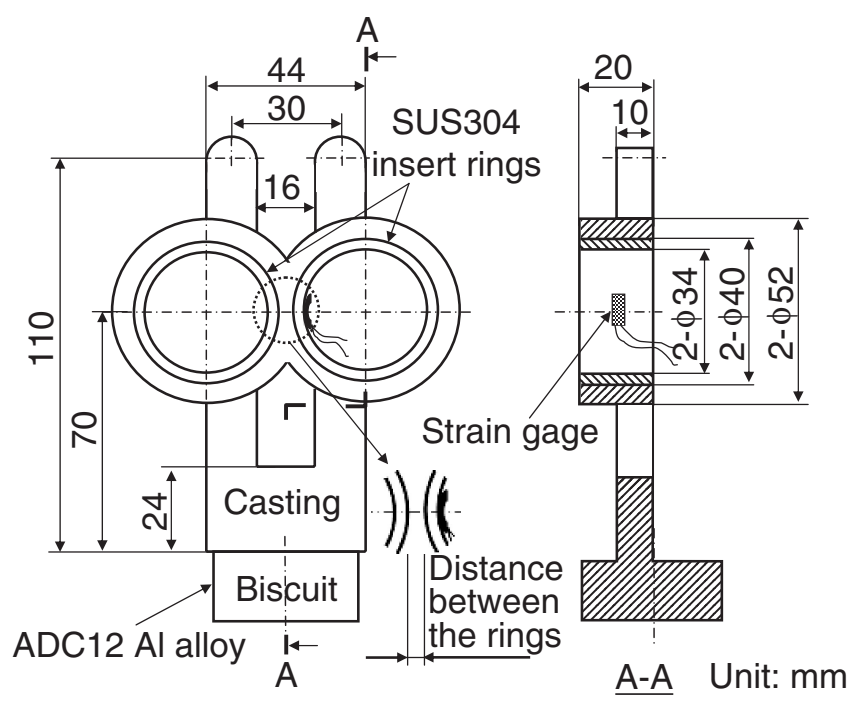

Fig. 1 Die casting for crack experiment.

Table 1 Conditions for die casting experiment.

\begin{tabular}{cccc}
\hline $\begin{array}{c}\text { Shot velocity } \\
(\mathrm{m} / \mathrm{s})\end{array}$ & $\begin{array}{c}\text { Casting pressure } \\
(\mathrm{MPa})\end{array}$ & $\begin{array}{c}\text { Melt temp. } \\
(\mathrm{K})\end{array}$ & $\begin{array}{c}\text { Die temp. } \\
(\mathrm{K})\end{array}$ \\
\hline 0.4 & 25 & 913 & 298 \\
\hline
\end{tabular}

Table 2 Chemical composition of AD12.1 aluminum alloy.

\begin{tabular}{ccccccccc}
\hline $\mathrm{Si}$ & $\mathrm{Fe}$ & $\mathrm{Cu}$ & $\mathrm{Mn}$ & $\mathrm{Mg}$ & $\mathrm{Zn}$ & $\mathrm{Ni}$ & $\mathrm{Sn}$ & $\mathrm{Al}$ \\
\hline 11.62 & 0.88 & 2.89 & 0.34 & 0.21 & 0.93 & 0.05 & 0.02 & Bal. \\
\hline
\end{tabular}

\subsection{Measurement of the mechanical properties of} ADC12 alloy die casting

AD12.1 alloy melt of a chemical composition identical to that used for the die casting experiments was die cast to plateshaped castings for machining tensile test specimens. The dimensions of the die casting for the tensile test specimens are shown in Fig. 2. The casting conditions were the same as that in section 2.1. Confirmed by transmission X-ray, the castings without defects such as shrinkages, entrapped gases, etc., were selected for machining the tensile test specimens. The specimens were cut out from the positions shown in Fig. 2 and machined by lathe to the final shapes for the tensile tests below $473 \mathrm{~K}$ and above $523 \mathrm{~K}$ respectively as illustrated in Fig. 3. In the machining, specimens observed any shrinkages or inclusions by visual inspection were excluded.

The tensile tests were carried out at seven temperatures $298,373,473,523,573,673$, and $773 \mathrm{~K}$ chosen from the range of room temperature to the solidus temperature of AD12.1 alloy. The strain rates during the cooling of the die casting for the experiments producing the cracks in the present study were estimated by simulation to be from 0 to $0.1 \mathrm{~s}^{-1}$ and the average strain rate, $0.05 \mathrm{~s}^{-1}$ was used as the strain rate for the tensile tests. The strain in the tensile tests was measured by a video camera and a differential transformer strain gages for the test below $473 \mathrm{~K}$ and over $523 \mathrm{~K}$ respectively. Each of the tensile test was started after the

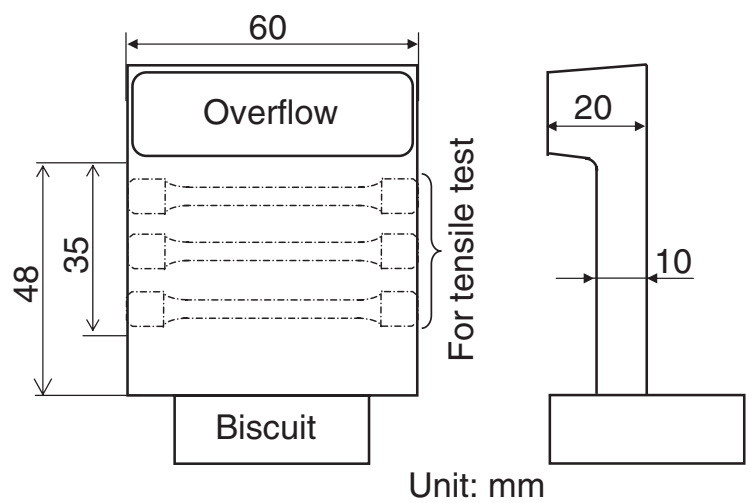

Fig. 2 Die casting for tensile test specimens.

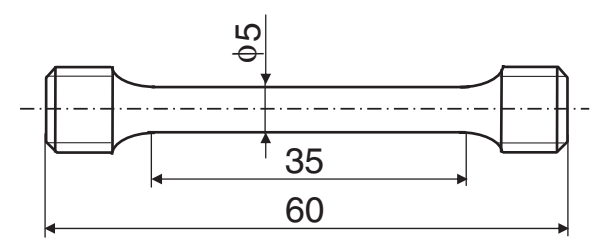

(a) For below 473K

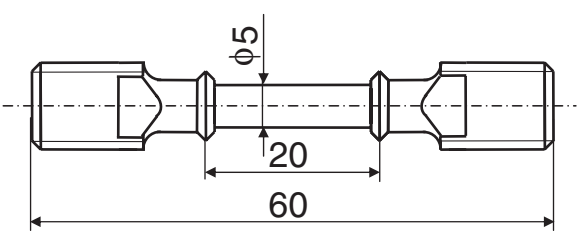

(b) For above 523K Unit: $\mathrm{mm}$

Fig. 3 Tensile test specimens.

specimen was kept for 5 minutes at a predetermined temperature. The temperature of the specimens was measured by a $0.1 \mathrm{~mm}$ diameter K-type thermocouple which was welded to the center of the specimen by resistance-welding. The mechanical properties of the SUS304 ring were also obtained by tensile tests with the JIS G0567 II-10 specimens machined from a $20 \mathrm{~mm}$ diameter bar under the same temperatures and strain rate as that for the $\mathrm{ADC} 12$ alloy die casting.

\subsection{Thermal stress simulation of the die casting}

To find out the relation between the occurrence of the cracks and the strain of the die castings, solidification and thermal stress simulations were conducted for the casting shown in Fig. 1. The materials of the die casting and the rings are AD12.1 alloy and SUS304 respectively. The material properties used for the simulation are given in Table 3 and Table 4. The FEM model was taken as half of the die casting because of its symmetric shape as shown in Fig. 4. The coupled thermal mechanical analysis was performed with the commercial structural analysis software MSC. MARC.

In the thermal analysis, heat transfer boundary condition was applied to the casting/mold, casting/ring, and ring/mold interfaces. Table 5 gives the heat transfer coefficients for each of the interfaces. The cavity of the mold at $298 \mathrm{~K}$ full of AD12.1 melt at $913 \mathrm{~K}$ was assumed as the initial condition of 
Table 3 Properties of ADC12 aluminum alloy used for thermal stress simulation.

\begin{tabular}{cccccccc}
\hline $\begin{array}{c}\text { Modulus of } \\
\text { elasticity } \\
(\mathrm{GPa})\end{array}$ & $\begin{array}{c}\text { Poisson's } \\
\text { ratio } \\
(-)\end{array}$ & $\begin{array}{c}\text { Density } \\
\left(\mathrm{kg} \cdot \mathrm{m}^{-3}\right)\end{array}$ & $\begin{array}{c}\text { Coefficient of linear } \\
\text { thermal expansion } \\
\left(\mathrm{K}^{-1}\right)\end{array}$ & $\begin{array}{c}\text { Specific } \\
\text { heat } \\
\left(\mathrm{J} \cdot \mathrm{kg} \cdot \mathrm{K}^{-1}\right)\end{array}$ & $\begin{array}{c}\text { Thermal } \\
\text { conductivity } \\
\left(\mathrm{W} \cdot \mathrm{m}^{-1} \cdot \mathrm{K}^{-1}\right)\end{array}$ & $\begin{array}{c}\text { Latent heat } \\
\left(\mathrm{kJ} \cdot \mathrm{kg}^{-1}\right)\end{array}$ & $\begin{array}{c}\text { Liquidus } \\
\text { temp. } \\
(\mathrm{K})\end{array}$ \\
\hline 76 & 0.3 & 2.67 & $2.06 \times 10^{-5}$ & 962 & 121 & $\begin{array}{c}\text { Solidus } \\
\text { temp. } \\
(\mathrm{K})\end{array}$ \\
\hline
\end{tabular}

Table 4 Properties of SUS304 stainless steel used for thermal stress simulation.

\begin{tabular}{ccccc}
\hline $\begin{array}{c}\text { Modulus of elasticity } \\
(\mathrm{GPa})\end{array}$ & $\begin{array}{c}\text { Poisson's ratio } \\
(-)\end{array}$ & $\begin{array}{c}\text { Density } \\
\left(\mathrm{kg} \cdot \mathrm{m}^{-3}\right)\end{array}$ & $\begin{array}{c}\text { Coefficient of linear } \\
\text { thermal expansion } \\
\left(\mathrm{K}^{-1}\right)\end{array}$ & $\begin{array}{c}\text { Specific heat } \\
\left(\mathrm{J} \cdot \mathrm{kg} \cdot \mathrm{K}^{-1}\right)\end{array}$ \\
\hline 192 & 0.28 & 8.03 & $1.71 \times 10^{-5}$ & $\begin{array}{c}\text { Thermal conductivity } \\
\left.\left(\mathrm{W} \cdot \mathrm{m}^{-1} \cdot \mathrm{K}\right)^{-1}\right)\end{array}$ \\
\hline
\end{tabular}

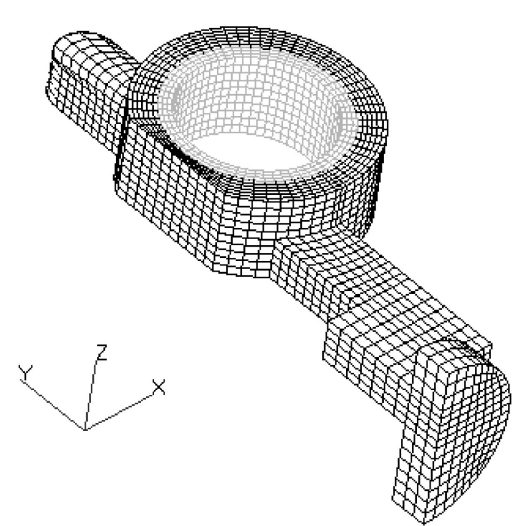

Fig. 4 FEM model for thermal stress simulation.

Table 5 Interface heat conductance used for thermal stress simulation.

\begin{tabular}{cccc} 
& & $\left(\mathrm{W} \cdot \mathrm{m}^{-2} \cdot \mathrm{K}^{-1}\right)$ \\
\hline $\begin{array}{c}\text { Castings (liquid)/ } \\
\text { Dies }\end{array}$ & $\begin{array}{c}\text { Castings (solid)/ } \\
\text { Dies }\end{array}$ & $\begin{array}{c}\text { Inserts/ } \\
\text { Dies }\end{array}$ & $\begin{array}{c}\text { Castings/ } \\
\text { Atmosphere }\end{array}$ \\
\hline 41840 & 8368 & 8368 & 837 \\
\hline
\end{tabular}

the thermal and stress analysis. The latent heat release of AD12.1 melt was treated by the equivalent specific heat method.

Both of the stress-strain behaviors of the ADC12 alloy die casting and the SUS304 rings were treated as elastoplastic as observed in the tensile tests and the stress-strain relations obtained at various temperatures in the tensile tests of section 2.2 were utilized in the stress analyses. Therefore, the temperature dependence of the elasticity and the yield stress gradients were taken into account for the ADC12 alloy die castings and the SUS304 rings in the stress simulation. The completely free sliding mechanical boundary condition was applied to the interface between the die casting and the rings.

\section{Results and Discussion}

\subsection{Occurrence of crack in the die casting}

Cracks were observed as the die casting was made with different distances between the two rings. One example of the appearance and the fractography of the crack is shown in Fig. 5. The crack occurred in the narrowest part of the casting between the two rings and showed a dimple-covered fractography. Thus, the crack can be considered as a cold crack but

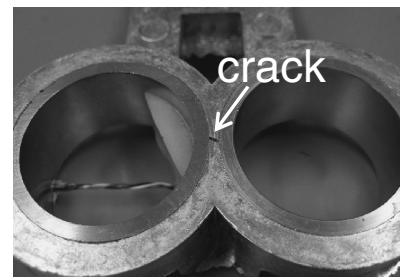

$10 \mathrm{~mm}$

Appearance

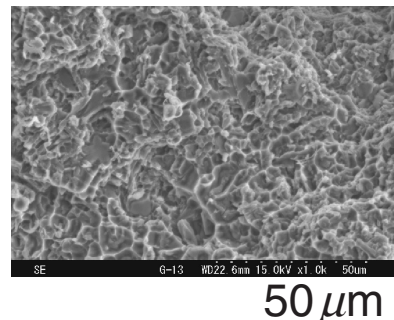

Fractography
Fig. 5 Crack of ADC12 die casting.

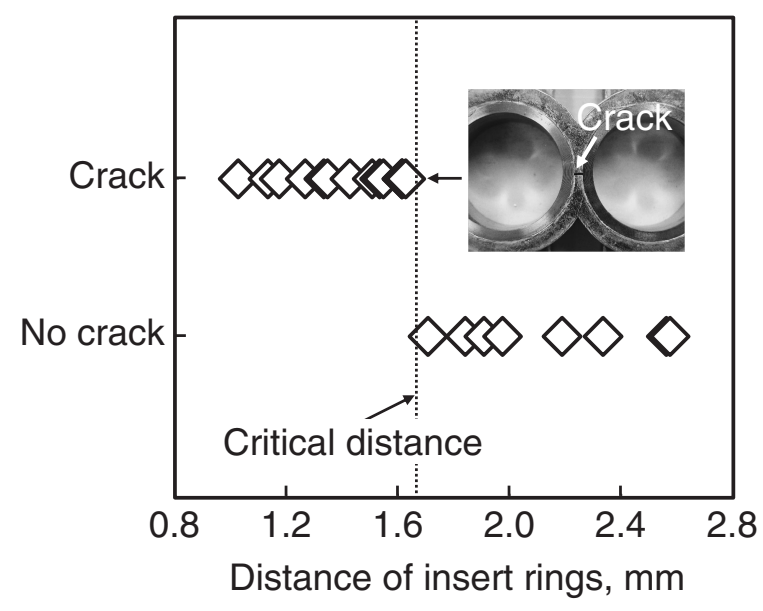

Fig. 6 Relation between crack and distance of insert rings.

not a hot crack according to the characters mentioned in section 1 . The relation between the crack occurrence and the distance of rings is illustrated in Fig. 6. It can be seen that no crack was observed when the distance of the rings exceeded $1.6 \mathrm{~mm}$, while the cracks were well reproducible when the distance between the rings was below $1.6 \mathrm{~mm}$.

To know the occurring time of the crack, the output of the strain gages installed on the inner surfaces of the rings was drawn in Fig. 7 together with the pressure change of the plunger in the die casting process. Compared with the strain curve of the gage installed on the ring of the die casting without a crack (Fig. 7(a), the distance between rings equals to $4 \mathrm{~mm}$ ), the strain curve of the cracked die casting showed an abrupt jump towards the tensile strain side in 3 second after melt injection. What this sudden change of the strain 


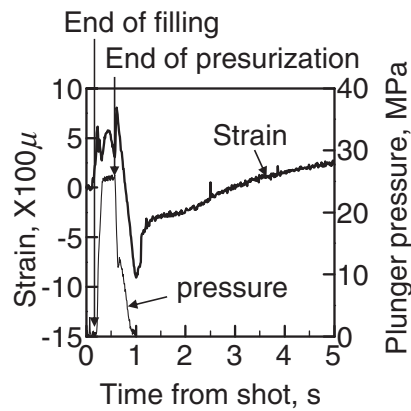

(a) Ring distance: $4 \mathrm{~mm}$ (No crack)

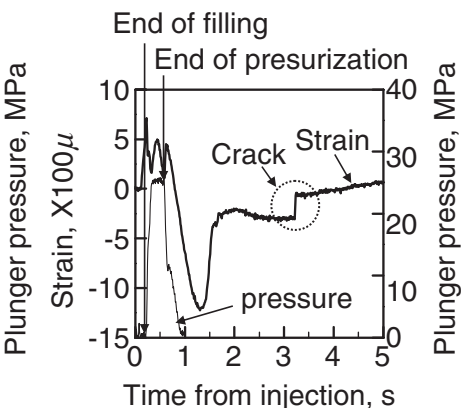

(b) Ring distance: $1.4 \mathrm{~mm}$

(Crack)
Fig. 7 Change of strains of the inner surfaces of rings.

means is considered as follows. The insert rings were compressed by the surrounding ADC12 alloy casting due to the thermal contraction in the solidification and cooling process. Here, if the casting between the rings fractures, the compressive force acting on the rings in the symmetric axial direction of the casting will become weaker thus the rings will deform elastically from the compressed state to give a little elongation in the symmetric axial direction. Because the gage was installed on the inner surface of the left side of the right side ring as shown in Fig. 1, it will be pulled a little bit when the casting between rings fractures. From the above consideration, the crack of casting can be considered as occurred in 3 second after melt injection.

\subsection{The temperature dependence of the fracture strain of ADC12 alloy die casting}

Through the above experiments, the critical distance between the rings to and the occurring time of the crack were determined. To examine the occurrence condition of the crack further, the fracture strains of ADC12 alloy die casting at different temperatures were investigated by tensile tests. The relation between the fracture strain and the test temperature was illustrated in Fig. 8. It was discovered from Fig. 8 that the fracture strain of ADC12 alloy die casting showed a relatively low value and a minor variation in the temperature range from room temperature to the vicinity of $600 \mathrm{~K}$, while it arises rapidly beyond $600 \mathrm{~K}$ with the increase of temperature. Focusing on this feature of the fracture strain, two tangent lines were drawn along the fracture strain curve and the temperature (573 K for the present composition of ADC12 alloy) corresponding to the intersection point of the two tangent lines was defined as the critical temperature to the ductility (hereinafter, called $T_{\mathrm{c}}$ temperature).

\subsection{Thermal stress analysis and crack criterion for ADC12 alloy die casting}

The equivalent strains (hereinafter, called strain) of castings both with and without the cracks were calculated in the process of solidification and cooling and compared with the fracture strain of ADC12 alloy die casting. The thermal stress simulations were conducted for the casting having a distance of $1.4 \mathrm{~mm}$ between the rings as a sample casting with the crack and the castings having distances of $2 \mathrm{~mm}$ and $4 \mathrm{~mm}$ between the rings as sample castings without the crack.

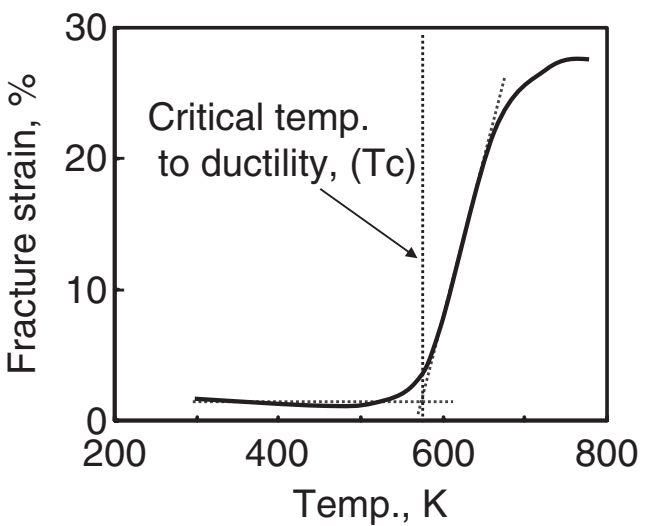

Fig. 8 Relation between fracture strain and temperature of ADC12 alloy die casting.

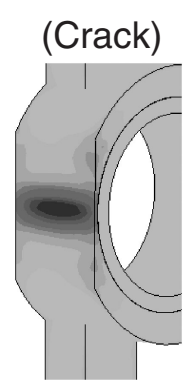

$1.4 \mathrm{~mm}$

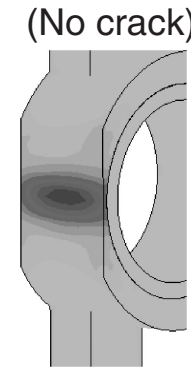

$2 \mathrm{~mm}$

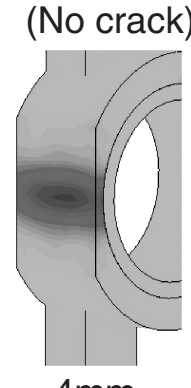

$4 \mathrm{~mm}$

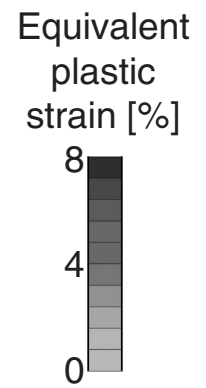

plastic

train $[\%]$

Distance of insert rings
Fig. 9 Strain distributions of ADC12 alloy die castings at $3 \mathrm{~s}$ after filling.

From the tensile test result in section 3.2, ACD12 alloy die casting showed an elastoplastic behavior even at room temperature and is not completely brittle. Therefore, it is appropriate to consider the occurrence condition of the crack for ACD12 alloy die casting in terms of the strain but not the stress. To investigate the relation between the crack occurrence and the strain that generated in the die castings during casting, the strain distributions in the die castings in 3 second (the time at which the crack occurred in the die casting having a distance of $1.4 \mathrm{~mm}$ between the rings) after melt injection are illustrated in Fig. 9. The maximum strain for each of the die casting is located at the same position, i.e., the narrowest part between the rings at which the crack occurred for the die casting of a distance of $1.4 \mathrm{~mm}$ between the rings. Nevertheless, the maximum value of the strain for each die casting is almost the same, about 7 8\%, no matter the crack occurred (The die casting with a distance of $1.4 \mathrm{~mm}$ between the rings) or not (The die castings with distances of $2 \mathrm{~mm}$ and $4 \mathrm{~mm}$ between the rings). At the same time, the strain distributions also do not show much difference.

To find the exact cause for the occurrence of the crack, the temperature dependence of the fracture strain of ADC12 alloy die casting was examined as related to the occurrence of the crack in the die castings. The fracture phenomena of the elastoplastic materials dealt with in fracture mechanics are generally limited to a definite temperature or a narrow range of temperature at which materials do not show large changes in the mechanical properties. In such a case, it can 


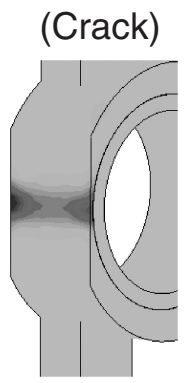

$1.4 \mathrm{~mm}$

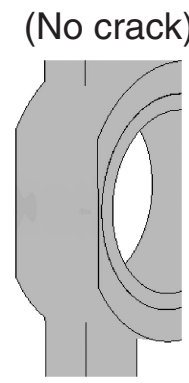

$2 \mathrm{~mm}$

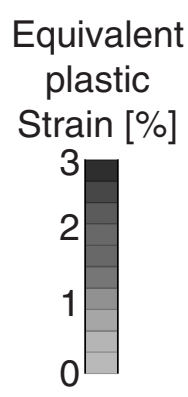

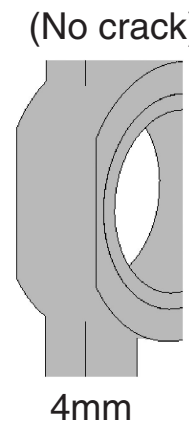

\section{Distance of insert rings}

Fig. 10 Strain distributions of ADC12 alloy die castings. (cumulative strain below $T_{\mathrm{c}}$.)

be considered that a material will crack when the strain generated in the material exceeds its fracture strain. However, the crack of die castings occurred in the cooling process with a temperature variation as large as several hundred degrees from the solidus temperature of ADC12 alloy to room temperature. That is to say, the total strain of die castings generated in the cooling process includes strains taking place at different temperatures. At the same time, the fracture strain of the die casting changes with temperature. Therefore, it is not clear which strain during the cooling of a casting is critical to the crack occurrence. At the same time, it is not clear which fracture strain measured of the cast material at different temperature should be used as the criterion of the crack occurrence.

The relation between the fracture strain of ADC12 alloy die casting and temperature, as shown in Fig. 8, is characterized of a turning point at $T_{\mathrm{c}}$ temperature. The fracture strain staying at a comparatively low value below temperature $T_{\mathrm{c}}$ increases rapidly with the rise of temperature beyond $T_{\mathrm{c}}$. Focusing on this feature of the fracture strain of ADC12 alloy die casting, the cumulative equivalent plastic strains generated in the die castings with a distance between the rings of $1.4 \mathrm{~mm}, 2 \mathrm{~mm}$ and $4 \mathrm{~mm}$ when the temperature changing from $T_{\mathrm{c}}$ to room temperature (hereinafter, called " $\varepsilon_{\mathrm{c}}$ strain") were calculated by thermal stress simulations and the distributions of the $\varepsilon_{\mathrm{c}}$ strain were illustrated in Fig. 10. The $\varepsilon_{\mathrm{c}}$ strain of the die casting with the occurrence of the crack (The distance between the rings was $1.4 \mathrm{~mm}$ ) was over $3 \%$, while those of the die castings without the occurrence of the crack (The distances between the rings were $2 \mathrm{~mm}$ and $4 \mathrm{~mm}$ ) all were under $0.5 \%$. It can be said that the occurrence of the crack corresponds well with the relation between the $\varepsilon_{\mathrm{c}}$ strain and the fracture strain of ADC12 alloy die casting. In addition, the highest strain appeared at the midpoint of the casting along the axial length of the ring in Fig. 9, while the highest strain appeared at the areas of the casting near the two ends of the axial length of the ring in Fig. 10.

Note that the strain in Fig. 9 includes the strain occurring above $T_{\mathrm{c}}$ temperature which may not contribute to the crack occurrence, while the strain in Fig. 10 considers only that below $T_{\mathrm{c}}$. The generating process of the cumulative strain $\varepsilon_{\mathrm{c}}$ was further discussed in some detail in the following.

To confirm the strain variation quantitatively further, the $\varepsilon_{\mathrm{c}}$ strains of the surface nodes at the center between the rings,

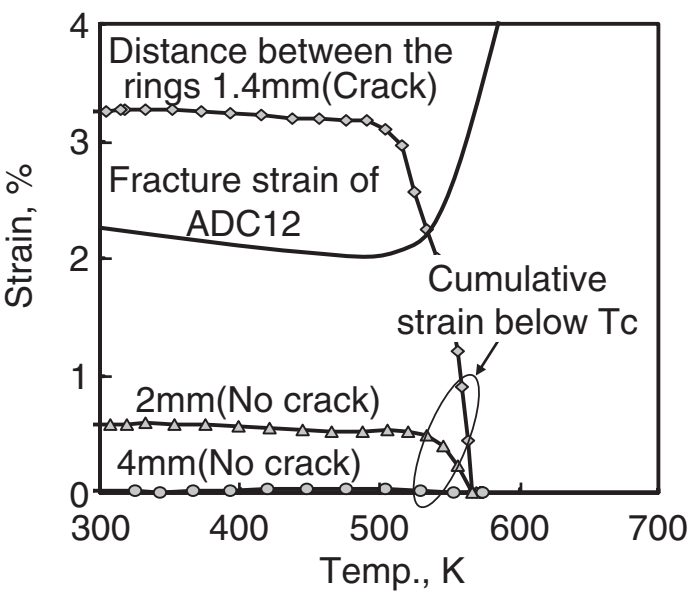

Fig. 11 Comparison of cumulative strain below $T_{\mathrm{c}}$ of die castings and fracture strain of ADC12 aluminum alloy.

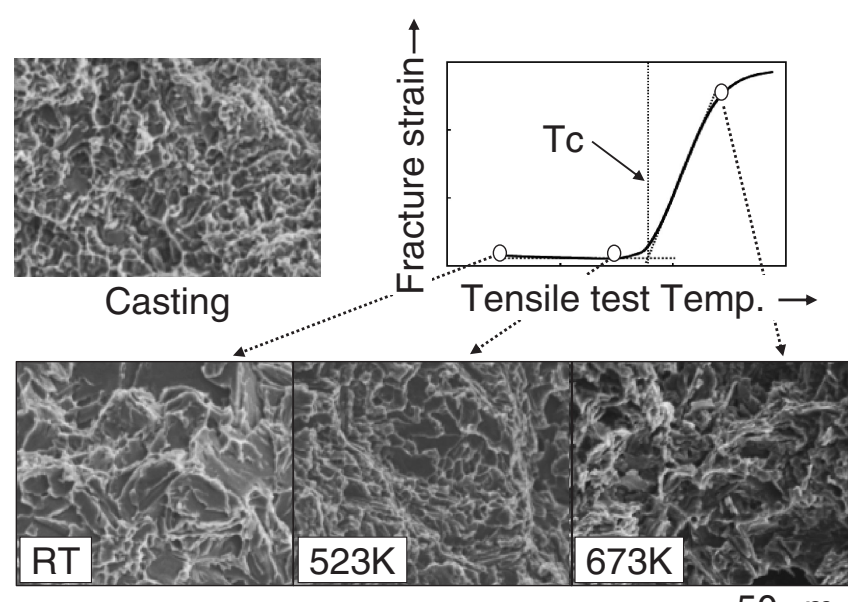

Tensile test specimens

$50 \mu \mathrm{m}$

Fig. 12 Fractographies of die castings and tensile test specimen.

i.e., the $\varepsilon_{\mathrm{c}}$ strains of the nodes showed the highest strain in Fig. 10, were extracted and compared with the fracture strain along the decrease of temperature from $573 \mathrm{~K}$ in the cooling processes. As illustrated in Fig. 11, the $\varepsilon_{\mathrm{c}}$ strain of the die casting with a distance of $1.4 \mathrm{~mm}$ between the rings was much higher than the fracture strain of ADC12 alloy die casting, while the $\varepsilon_{\mathrm{c}}$ strains of the die castings with distances of $2 \mathrm{~mm}$ and $4 \mathrm{~mm}$ between the rings were much lower than the fracture strain of ADC12 alloy die casting.

According to the result shown in Fig. 11, the $\varepsilon_{\mathrm{c}}$ strain of the die casting with a distance of $1.4 \mathrm{~mm}$ between the rings intersected the curve of the fracture strain of ADC12 alloy die casting in the temperature range between $540 \mathrm{~K}$ and $500 \mathrm{~K}$ in the cooling process. That is to say, the crack can be considered to have occurred in the temperature range between $540 \mathrm{~K}$ and $500 \mathrm{~K}$. From the thermal simulation of the die casting, the temperature of the node where the cold crack occurred reached between $540 \mathrm{~K}$ to $500 \mathrm{~K}$ in about 3 seconds after melt filling, which is in good agreement with the occurrence time of the crack as observed in the die casting experiment. In Fig. 12, the fractography of the crack occurred in the die casting with a distance of $1.4 \mathrm{~mm}$ between the rings was compared with the fractographies of the 
specimens tensile tested at various temperatures. It was observed that the crack fractograph of the die casting was most similar to that of the specimen tested at $523 \mathrm{~K}$ which is just between $540 \mathrm{~K}$ and $500 \mathrm{~K}$.

Through the above examinations of the die casting experiments and the thermal stress simulations, it can be said that the occurrence of the cold crack in ADC12 alloy die castings can be judged by comparing the $\varepsilon_{\mathrm{c}}$ strain with the fracture strain of ACD12 alloy die casting, i.e., the $\varepsilon_{\mathrm{c}}$ strain exceeding the fracture strain of ADC12 alloy die casting can be adopted as a criterion for the occurrence of the cold crack. Therefore, it is possible to predict the occurrence of the cold crack and its position in a $\mathrm{ADC} 12$ alloy die casting by calculating the distribution of the $\varepsilon_{\mathrm{c}}$ strain, i.e., the cumulative strain from $T_{\mathrm{c}}$ temperature to room temperature in the casting process.

\section{Conclusions}

The occurrence phenomenon of the cold crack in ADC12 alloy die castings and its occurrence criterion were investigated by die casting experiments, tensile tests and thermal stress simulations. The following conclusions were obtained.

(1) The fracture strain of ACD12 alloy die casting increases rapidly with the rise of temperature beyond $573 \mathrm{~K}$, this temperature corresponding to the turning point of the fracture strain was defined as the critical temperature to the ductility of ADC12 alloy die casting ( $T_{\mathrm{c}}$ temperature).

(2) The cold crack observed in ADC12 alloy die castings can be explained by the following cold crack occurrence criterion. The cold crack will occur when the cumulative equivalent plastic strain generated below $T_{\mathrm{c}}$ (the $\varepsilon_{\mathrm{c}}$ strain) exceeds the fracture strain of ADC12 alloy die castings.

(3) It is possible to predict the occurring positions of cold cracks in ADC12 alloy die castings through calculating the distributions of the equivalent plastic strain generated below $T_{\mathrm{c}}$ (the $\varepsilon_{\mathrm{c}}$ strain) by thermal mechanical simulation.

\section{Acknowledgment}

We are deeply grateful to Dr. Eng. Eisuke Niyama for his helpful comments and advice.

\section{REFERENCES}

1) D. G. Eskin and L. Katgerman: Metall. Mater. Trans. 38A (2007) 15111519.

2) K. Agatsuma: Kinzoku Kougaku Kouza 5, Kakou Hen I, Youkai Chuzo.Imono, (Asakura Shoten, 1969) p. 285.

3) B. G. Thomas: ISIJ Int. 35 (1995) 737-743.

4) Nihon Chuzo kougakai Daikasuto Kenkyubukai: Daikasuto no Chuzokekkan.Furyo oyobi Taisaku Jirei Shu, (Japan Foundry Engineering Society, 2000) p. 45.

5) D. G. Eskin, Suyitno and L. Katgerman: Progress Mater. Sci. 49 (2004) 629-711.

6) H. F. Bishop, C. G. Ackerlind and W. S. Pellini: AFS Trans. 60 (1952) 818-833.

7) J. Vero: Met. Industry 48 (1936) 431-455.

8) E. Niyama: Japan-US Joint Seminar on Solidification of Metals and Alloys, Tokyo (Japan Society for Promotion of Science) (1977) pp. 271282.

9) H. Fredriksson, M. Haddad-Sabzevar, K. Hansson and J. Kron: Mater. Sci. Technol. 21 (2005) 521-529. 